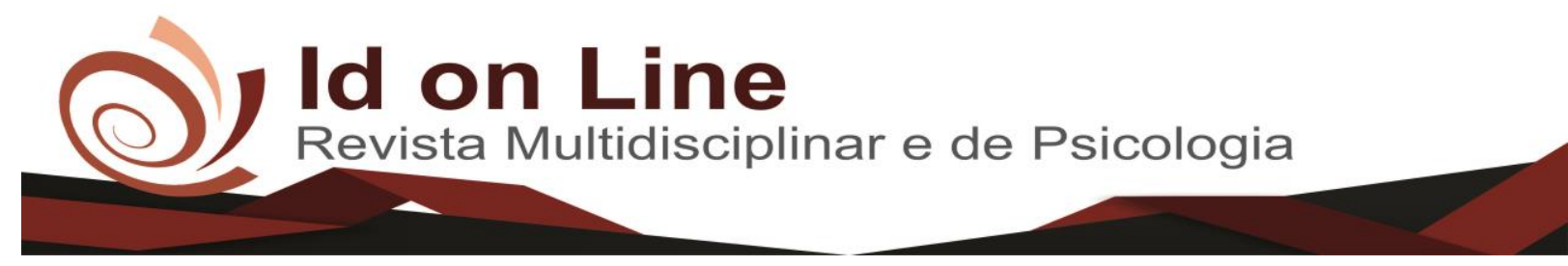

Artigo

\title{
Potencial Antimicrobiano do Óleo da Folha de Eucalyptus urograndis Frente Stafilococus aureus
}

\author{
Raquel Cotrim Cardoso ${ }^{1}$; Allana Leão Alcântara ${ }^{2}$; Flavio Mendes de Souza ${ }^{3}$; \\ Marcelo José Costa Lima Espinheira ${ }^{4}$
}

\begin{abstract}
Resumo: A busca por maneiras alternativas e não invasivas no controle de infecções tornou-se o principal objetivo de muitos grupos de pesquisa voltados para a química medicinal e farmacológica. Neste contexto é reconhecido, que diversas espécies de plantas podem ser utilizadas para fins profiláticos e curativos de infecções. O presente estudo tem por objeto a avaliação e determinação do potencial antimicrobiano do óleo essencial extraído do Eucalyptus urograndis através de técnicas de inibição na formação de colônias de bactérias do gênero Staphylococcus aureus ATCC 12692, Staphylococcus epidermides ATCC 12228 , Escherichia coli ATCC 29214 e técnica de disco-difusão. Os resultados indicam que o óleo extraído do Eucalyptus urograndis possui atividade antimicrobiana frente a Staphylococcus aureus. Porém se faz necessário à realização de estudo mais aprofundado para ponderar possíveis efeitos citotóxicos sobre as células eucariontes, a fím de julgar a possibilidade da criação de novos bioprodutos.
\end{abstract}

Palavras-chave: óleo, poder antimicrobiano, folha, eucalipto.

\section{Antimicrobial Potential of Eucalyptus urograndis Leaf Oil Front Staphylococcus aureus}

\begin{abstract}
The search for alternative and noninvasive ways in infection control has become the primary goal of many research groups focused on medicinal and pharmacological chemistry. In this context it is recognized that various species of plants can be used for prophylactic and curative purposes of infections. The present study aims to evaluate and determine the antimicrobial potential of the essential oil extracted from Eucalyptus Urograndis through inhibition techniques in the formation of colonies of bacteria of the genus Staphylococcus aureus ATCC 12692, Staphylococcus epidermides ATCC 12228, Escherichia coli ATCC 29214, and disc-diffusion technique. The results indicate that the oil extracted from Eucalyptus Urograndis has antimicrobial activity against Staphylococcus aureus. However, it is necessary to carry out a more in-depth study to consider possible cytotoxic effects on eukaryotic cells, in order to judge the possibility of creating new bioproducts.
\end{abstract}

Key words: oil, antimicrobial power, leaf, eucalyptus.

\section{Introdução}

A Organização Mundial da Saúde (OMS) tem apontado e incentivado estudos sobre a utilização de plantas medicinais, com o objetivo de avaliar cientificamente os benefícios e

\footnotetext{
${ }^{1}$ Raquel Cotrim Cardoso - Graduanda em Farmácia na FAINOR contato: raquelcotrimc@ gmail.com;

2 Allana Leão Alcântara - Graduanda em Farmacia na FAINOR contato: allanal.farm@ gmail.com;

3 Flavio Mendes de Souza, graduado em Química pela Universidade estadual de Santa Cruz - UESC, mestre em química pela Universidade Estadual da Bahia - UESB. Docente da Faculdade Independente do Nordeste - FAINOR;

${ }^{4}$ Marcelo José Costa Lima Espinheira, biologo graduado pela Universidade Católica de Salvador - UCSAL, Pós graduado em Metodologia e Gestão do Ensino Superior pela Faculdade Independente do Nordeste - FAINOR, mestre em Religião/educação na linha de pesquisa sobre ética e gestão pela faculdade EST. Docente da Fainor, FTC e UNINASSAU. 
segurança de medicamentos. Ao final da década de 1970 a OMS criou o Programa de Medicina Tradicional que recomenda aos estados-membros o desenvolvimento de políticas públicas para facilitar a integração da medicina tradicional e da medicina complementar alternativa nos sistemas nacionais de atenção à saúde, assim como promover o uso racional dessa integração (BRASIL, 2006).

No Brasil a grande diversidade de fitoterápicos é relatada em muitos estudos, especialmente por ser um país tropical, abrangendo espécies como da família Myrtaceae, uma das plantas mais utilizadas pelo seu potencial medicinal. A família Myrtaceae compreende cerca de 140 gêneros e 3.500 espécies de árvores e arbustos que estão distribuídas em regiões tropicais e subtropicais da Austrália, Ásia e América (ANGIOSPERM PHYLOGENY GROUP III, 2009). A família Myrtaceae é dividida nas subfamílias: Myrtoideae (com frutos do tipo baga e folhas opostas), encontradas principalmente na América do Sul e Central e na Austrália e Leptospermoideae (com frutos do tipo cápsulas ou núculas e folhas alternas ou opostas), com maior concentração na Austrália.

A família Myrtaceae apresenta grande potencial econômico (e.g. alimentação, ornamentação e farmacológico), muitas de suas espécies são utilizadas na alimentação, a exemplo de Psidium guajava L. (goiaba) e Eugenia uniflora L. (pitanga), consumidas em grande escala em suco, doces, geleias e sorvetes. Na ornamentação, destacam-se as espécies (Eugenia sprengelii DC e Leptospermums coparium e como medicinais destacam-se espécies dos gêneros Eucalyptus e Myrciaria (LORENZI et al., 2006).

O gênero Eucalyptus é procedente da Austrália e possui em torno de 680 espécies. O eucalipto foi introduzido no Brasil em 1903 com o melhoramento genético feito por Edmundo Navarro de Andrade, com o intuito de produzir a madeira para o carvão e dormentes para estrada de ferro, bem como para o reflorestamento das áreas nativas que haviam sido derrubadas.

O Eucalyptus é considerado o gênero florestal mais importante no Brasil, devido a sua extensa área plantada e seu potencial de utilização nas industriais como matéria-prima. As diversas espécies do gênero possuem capacidade de crescer rapidamente, caracterizando-as como uma matéria prima importante, principalmente na produção de celulose e papel. Além disso, a madeira do eucalipto é utilizada freqüentemente como combustível nas empresas (BRISOLA; DEMARCO, 2011).

Uma das principais vantagens ambientais de áreas florestadas com o Eucalyptus é a redução das ações erosivas de solo, passagem de nutrientes das esferas mais profundas do solo para as mais superficiais, seqüestro de carbono; geração de excelente camada de material 
orgânico envolvendo a umidade do solo e diminuição da temperatura do micro-clima (FARIA et al. 2013).

A espécie Eucalyptus urograndis possui o diâmetro e o porte em altura igual ao das duas espécies que lhe deram origem, isso a concede uma madeira de qualidade (FARIA et al., 2013). Este híbrido originado do cruzamento entre E. urophylla com E. grandis, tem sido descrito como uma planta de desenvolvimento rápido, adaptável a diferentes condições climáticas, resistente à doenças, dando origem à produtos de qualidade (BENATTI et al., 2013). Devido à essas características, o híbrido é bastante utilizado no cultivo brasileiro (PALUDZYSZYN et al., 2004).

A indústria farmacêutica e de cosméticos denotam interesse no gênero Eucalyptus, devido à diversidade de espécies, dentre elas, algumas são usadas pela medicina popular desde os tempos mais antigos (DUARTE et al., 2010) até os dias atuais (CARNEIRO et al., 2014), e possíveis estudos de substâncias encontradas em plantas que tem efeito tóxicomínimo se faz de fundamental importância para saúde mundial (DE PINHO et al., 2012).

Os óleos essenciais isolados de Eucalyptus são sintetizados e armazenados por células secretoras presentes nas folhas (VITTI; BRITO, 2003). O óleo essencial extraído das folhas das plantas deste gênero possuem característica de um líquido amarelo ou incolor, raramente de cor castanho ou verde, fluido, apresentando cheiro forte, perfumado e de sabor apimentado, tendo como compostos relevantes, o 1,8-cineol (eucaliptol), felandreno, piperitona e aldeídos voláteis. Muitos componentes do óleo essencial de folhas de Eucalyptus possuem efeitos tóxicos.

Os óleos essenciais estão sendo amplamente utilizados no combate ao crescimento e desenvolvimento de microrganismos. Um grande número de óleos essenciais permite ação in vitro frente a micro-organismos, por outro lado, a ação antimicrobiana presente nos alimentos é consideravelmente menor (BURT, 2004). Outro fator que favorece o crescimento de pesquisas voltadas à característica antimicrobiana dos óleos essenciais é a procura cada vez maior pelos consumidores, por fabricação de linhagens naturais com o menor nível possível de aditivos e conservantes (SILVA et al., 2014).

Em vista dos argumentos apresentados, a análise do poder antimicrobiano das folhas do Eucalyptus urograndis frente aos microrganismos Staphylococcus aureus, Staphylococcus epidermides e Escherichia coli, é de grande relevância para a sociedade, pois permitirá melhor entendimento dos benefícios da utilização desse óleo essencial no tratamento das doenças infecciosas, além de contribuir para que a população mundial tenha conhecimento sobre o potencial poder antimicrobiano do mesmo (BRISOLA; DEMARCO, 2011). 
O objetivo do presente estudo foi avaliar a ação microbiológica do óleo extraído da folha do Eucalipto urograndis, frente a ação de bactérias dos gêneros Staphylococcus aureus ATCC 12692, Staphylococcus epidermides ATCC 12228, Escherichia coli ATCC 29214. Para considerou-se necessário também:

- Realizar a extração do óleo da folha do Eucalipto urograndis utilizando o método de hidrodestilação que é empregado através do uso do aparelho clevengem.

- Verificar o poder antimicrobiano do óleo por meio do teste de difusão em Agar, este é um método físico o qual as bactérias escolhidas são aplicadas em um meio de cultura sólido relacionando o tamanho do halo formado com o seu poder antimicrobiano.

- Caracterizar a ação antimicrobiana por meio da determinação de uma pequena quantidade suficiente para impedir o crescimento das bactérias escolhidas, conhecido como Concentração Inibitória Mínima (CIM), utilizando óleo da folha do Eucalipto urograndis.

\section{Metodologia}

\section{Conduções dos Experimentos}

Os experimentos foram conduzidos na Instituição de Ensino Superior Faculdade Independente do Nordeste - FAINOR, no setor dos laboratórios de saúde. Os processos que foram executados durante o experimento seguiram os padrões descritos na CLSI - Clinical Laboratory Standard Institute, determinado pela ANVISA., obedecendo os seguintes requisitos:

\section{Coleta e Preparação da Amostra}

As folhas utilizadas no processo de extração foram coletadas em um plantio de Eucaliptos urograndis situado no município de Planalto - Ba, em agosto de 2017, entre as coordenadas geográficas - $14^{\circ} 42^{\prime} 39.8^{\prime}$ ' S e 40³1'49.1 W. A identificação e armazenamento da exsicata foi feita no Herbário da Universidade Estadual do Sudoeste Baiano - UESB, Campus de Vitória da Conquista, Bahia, Brasil.

Sendo coletadas folhas da planta alvo da pesquisa (Eucalyptus urograndis), que estavam livres de doenças, parasitas, em seguida foi higienizado o material coletado com a 
finalidade de eliminar prováveis interferentes, deixando secar por uma semana sob luz solar para evitar a contaminação por microrganismos.

\section{Extrações do Óleo}

O material foi colocado sobre papel-alumínio e levados a estufa por 10 minutos a uma temperatura de $100^{\circ} \mathrm{C}$, posteriormente com o ajuda de um liquidificador triturou-se o material; a cada trituração foi pesado o material em balança analítica, o equipamento utilizado para trituração foi higienizado para que não ocorresse interferência nos resultados, sendo utilizado $200 \mathrm{~g}$ da folha e $1000 \mathrm{ml}$ de água, onde passou pelo clevenger para que fosse feita a extração do óleo da folha.

Foi utilizado o método de hidrodestilação que é empregado através do uso do aparelho clevengem. Neste método, o material vegetal conserva-se em contato com a água em ebulição, o vapor promove o rompimento das paredes celulares onde sucede a evaporação do óleo que fica entre as células da planta. Pelo condensador passa o vapor, que consiste na mistura de água e óleo, local onde ocorre seu resfriamento (SILVA, 2011) logo após ocorre a constituição de duas fases líquidas podendo ser separadas (SATOR, 2009).

Para realização da separação do óleo e água foi utilizado o rotaevaporador que através dos processos de condensação e evaporação, elimina substâncias diferentes que podem conter as amostras. A amostra que foi separada e adicionada no balão de fundo redondo que, continua em banho Maria. Neste lugar o balão passa por rotações consecutivas ocasionada pelo equipamento, o qual vai promover o aumento da superfície de contato da parede da vidraria, e conseqüentemente do extrato bruto para potencializar a evaporação.

\section{Avaliação Antimicrobiana por Disco de Difusão}

Para analise antimicrobiana foi realizado o método de difusão em agar utilizando disco de papel adsorvente estéril medindo $6 \mathrm{~mm}$ de diâmetros que foram embebidos com a solução do óleo essencial da folha, de forma que cada disco apresentou concentração de $1.000 \mu \mathrm{g} / \mathrm{ml}$. Para esta técnica foram preparadas placas de Agar Mueller Hington, utilizando-se os seguintes microrganismos: Escherichia coli, Staphylococcus aureus e Staphylococcus epidermidis, os procedimentos adotados seguiram a seguinte ordem: 
I. Suspensão do microrganismo em solução salina estéril, onde com uma alça de platina foram transferidos de 3 a 4 colônias do agente até obter-se a turvação encontrada na escala 0,5 de MacFarland;

II. Para realizar a semeadura utilizou-se a técnica de distensão, na qual um swab estéril é introduzido na suspensão bacteriana (o swab foi comprimido na parede do tubo para retirar o excesso do inoculo) em seguida semeou a superfície do agar em três direções diferentes, deixando a placa em repouso para que o meio absorvesse o inoculo, o tempo variou de 3 a 5 minutos posteriormente os discos foram adicionados e a placa foi levada para estufa de incubação (não ultrapassou o período de 15 minutos entre semeadura e adição dos discos); e

III. Ao fim do período de 24 horas observou-se a formação dos halos, que foram medidos com auxílio de uma régua.

\section{Avaliação da Concentração Inibitória Mínima}

Foi utilizado para confirmação da ação antimicrobiana o método de diluição em caldo feito em tubos de ensaio. Soluções de estoque dos óleos essenciais foram preparados misturando $1 \mathrm{ml}$ do oleo com $9 \mathrm{ml}$ de álcool absoluto em tubos de ensaio para obtenção da solução mãe, sendo realizada por seguidas diluições a 1:10, 1:100 e 1:1000.

Tubos de ensaio foram preparados contendo $8 \mathrm{ml}$ do meio Muller- Hinton liquido, posteriormente dividiu 5 tubos em três grupos para realização da segunda diluição.

A partir desses tubos foram adicionados $1 \mathrm{ml}$ de cada solução mãe em tubos 1, 2, 3, 4 e 5 acrescentando 0,5 $\mathrm{ml}$ das estripes da bactéria Staphylococcus aureus em seqüência a diluição ocorreu de forma consecutiva até finalizar os tubos que foram incubados a $37^{\circ} \mathrm{C}$, no período de 24 horas.

Também foram preparados controles para realização de uma provável comparação de turvação entre os tubos com as respectivas diluições. Três tubos foram feitos, sendo que no primeiro tubo apresentava apenas o meio Muller-Hinton liquido, no segundo foi adicionado o meio Muller-Hinton líquido mais $0,5 \mathrm{ml}$ das estripes da bactéria $S$. aureus e o ultimo tubo foi preparado com $8 \mathrm{ml}$ do meio Muller-Hinton líquido, 0,5 $\mathrm{ml}$ das estripes de bactéria e $1 \mathrm{ml}$ do antibiótico Vancomicina 500mg, que foi diluída em solução de cloreto de sódio, sendo incubados a $37^{\circ} \mathrm{C}$ no período de 24 horas. 
Para validação do método de concentração inibitória mínima por diluição em caldo foram retirados 10 micro-litros da diluição de 1:100 e 1:1000 e semeados na placa de petri, colocados na estufa na temperatura de $37^{\circ} \mathrm{C}$, no período de 24 horas para observação do crescimento bacteriano.

\section{Resultados e Discussão}

\section{Percentual de Rendimento do Oléo Essencial}

A extração do óleo da folha, feita com $200 \mathrm{~g}$ de folhas verdes do Eucaliptos urograndis e $1000 \mathrm{ml}$ de água destilada, apresentou rendimento de $0,5 \%$, correspondente ao volume de $1 \mathrm{ml}$, pesando $1,1584 \mathrm{~g}$.

O óleo extraído da folha do Eucaliptos urograndis, é constituído por componentes como 1,8-cineol, citronelal, citronelol, acetato de citronelila, p-cimeno, eucamalol, limoneno, linalol, $\beta$-pineno, $\gamma$-terpineno, $\alpha$-terpinol, aloocimeno e aromadendrene. BURT e colaboradores (2014) associaram essas estruturas químicas com atividades antimicrobianas importantes.

\section{Analise do Poder Antimicrobiano pela Técnica de Difusão em Ágar}

O método de disco-difusão foi descrito por Bauer e colaboradores (1966), e desde então tem sido amplamente utilizado nos laboratórios de microbiologia. Este método baseia-se no princípio da difusão, através do ágar, de um antimicrobiano que leva à formação de um halo de inibição do crescimento bacteriano, cujo diâmetro é inversamente proporcional à concentração inibitória mínima (MIC) (BARRY., al., 1991; JORGENSEN et al., 1999). Esse método permite classificar se a amostra bacteriana é sensível ou resistente à determinada solução (NATIONAL COMMITTEE FOR CLINICAL LABORATORY STANDARDS, 2000).

Os materiais utilizados no teste de disco-difusão são consideravelmente baratos e não exige a utilização de equipamentos especiais. Além disso, é uma técnica prática e de fácil execução, utilizado especialmente para bactérias de crescimento rápido e apresenta grande flexibilidade na escolha do número e tipo de antimicrobianos a serem testados (JORGENSEN, 1997; JORGENSEN, 1998). 
Para avaliar o poder antimicrobiano do óleo extraído da folha do Eucalyptus urograndis foi realizada a técnica de difusão em ágar. Houve formação de um halo de inibição de $15 \mathrm{~mm}$ pelo óleo extraído (Figura 1), em um meio contendo microorganismos de morfologia Grampositiva (Staphylococcus aureus), por sua vez o halo apresentado pela vancomicina foi de 20mm (Figura 2), demonstrando resultado significativo, uma vez que de acordo com a tabela de halos, a sensibilidade da vancomicina é considerada quando o diâmetro do halo é superior ou igual a $14 \mathrm{~mm}$, conforme mostra a tabela 1.

Tabela 1: Atividade antibacteriana do óleo

\begin{tabular}{|c|c|c|c|c|c|}
\hline \multirow[b]{2}{*}{ Microorganismo } & \multirow[b]{2}{*}{ Agente } & \multirow{2}{*}{$\begin{array}{l}\text { Halo formado } \\
\text { pelo óleo }\end{array}$} & \multicolumn{3}{|c|}{ Halos de inibição (mm) } \\
\hline & & & $\mathrm{R}$ & I & $\mathrm{S}$ \\
\hline $\begin{array}{l}\text { Staphylococcus } \\
\text { aureus }\end{array}$ & Vancomicina & $15 \mathrm{~mm}$ & $\leq 14$ & $15-16$ & $\geq 17$ \\
\hline E. coli & Ciprofloxacino & $00 \mathrm{~mm}$ & $\leq 15$ & $16-20$ & $\geq 21$ \\
\hline S. epidermidis & Vancomincia & $00 \mathrm{~mm}$ & $\leq 14$ & $15-16$ & $\geq 17$ \\
\hline
\end{tabular}

Fonte: Kirby e Bauer, 2011

O óleo extraído não apresentou poder antimicrobiano frente aos microorganismos $E$. coli e S. epidermidis, pois não houve formação de halo de inibição através da técnica de difusão em ágar.

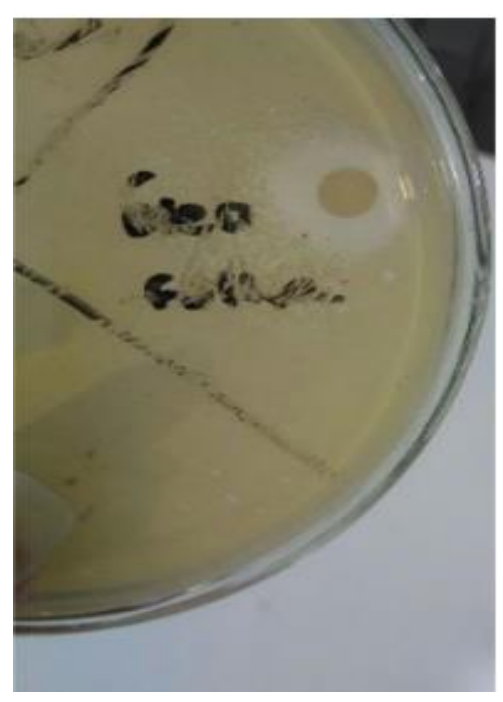

Figura 1. Halo de inibição do óleo do Eucalyptus urograndis

Fonte: elaborada pelo autor

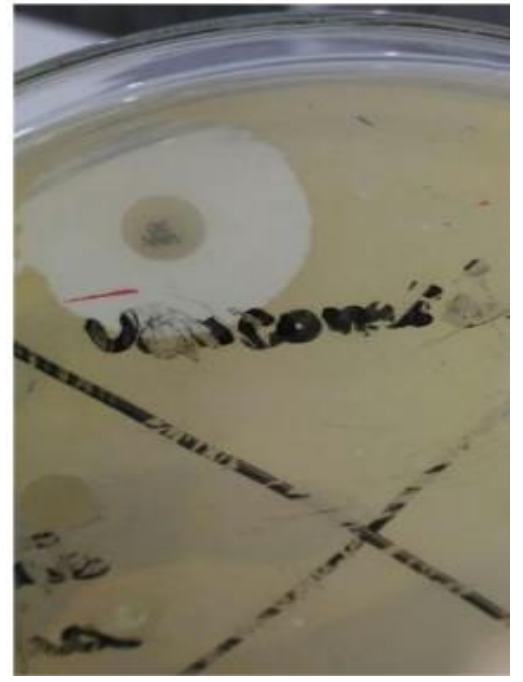

Figura 2. Halo de inibição da vancomicina

Fonte: elaborada pelo autor 
Bachir e Benali (2012) determinaram a atividade antimicrobiana de óleos essenciais extraídos de Eucaliptos globulos, através do método de difusão em disco de ágar e método do caldo de diluição para as cepas bacterianas E. coli e S. aureus.

Observou-se que, tanto pelo método em caldo quanto pelo método de disco difusão em ágar, o óleo essencial de Eucaliptos glóbulos inibiu o crescimento bacteriano dos microorganismos E. coli e S. aureus, enfatizando que quanto maior a concentração do óleo, maior é a inibição do crescimento de bactérias.

Resultados semelhantes foram relatados na literatura, quanto à atividade antimicrobiana do óleo essencial da folha de E. globulus e de espécies semelhantes (WARNKE et al., 2009), reforçando que a utilização dos óleos essenciais extraídos, em altas concentrações demonstram potentes efeitos inibitórios de bactérias, considerando a sensibilidade desses microorganismos ao óleo (BACHIR; BENALI 2012).

\section{Concentração Inibitória Mínima Por Diluição Em Caldo}

Para maior comprovação da atividade antimicrobiana do óleo de E. urograndis, realizou-se o método de diluição em caldo. Este método consiste em uma macro-diluição que associa a dimensão do crescimento bacteriano em meio líquido e a concentração do óleo extraído da folha do E. urograndis. A determinação do crescimento bacteriano é feita a partir da avaliação da turbidez provocada pelo crescimento microbiano.

A comparação do poder inibitório do óleo foi feita através das diluições de 1:10, 1:100 e 1:1000. A turbidez na diluição de 1:10 e 1:100 foi mais aparente quando comparadas com a diluição de 1:1000, como mostra a figura 3.

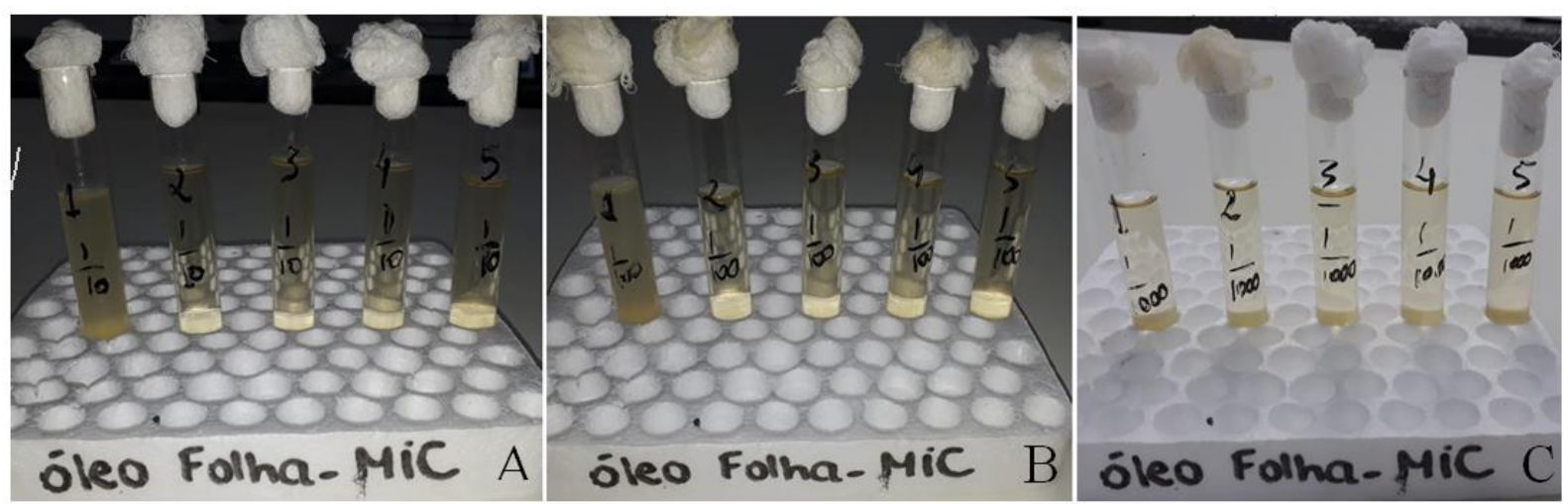

Figura 3. Foto ilustrativa da diluição em caldo nas concentrações de (A) 1:10, (B) 1:100 e (C) 1:1000 Fonte: Elaborada pelo autor 
Para confirmar a concentração inibitória mínima por diluição em caldo, foi realizada semeadura em placa de petri com $10 \mu 1$ do caldo da diluição para observar o crescimento bacteriano. Na diluição de 1:1000 houve crescimento de poucas colônias de bactérias e a medida que a semeadura foi realizada nas placas com $10 \mu \mathrm{l}$ dos tubos $1,2,3,4$ e 5, respectivamente, o crescimento bacteriano aumentou (Figura 4), isso ocorre porque a concentração do óleo diminui devido à diluição, tendo como consequiência a redução do poder antimicrobiano.

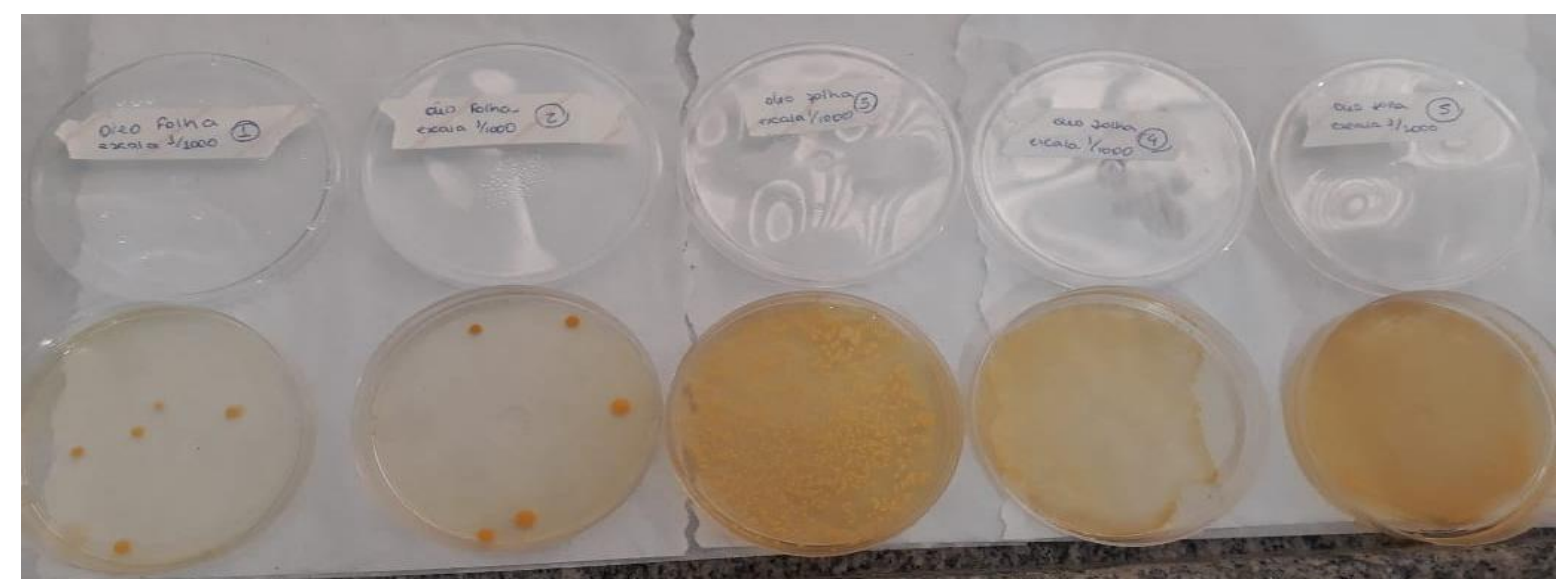

Figura 4. Semeadura em placa com diluição de 1:1000 Fonte: Elaborada pelo autor

Na diluição de 1:100 não houve crescimento de bactérias em nenhuma das placas semeadas (Figura 5), dessa forma, sugere-se que nessa concentração o óleo possui maior efeito inibitório.

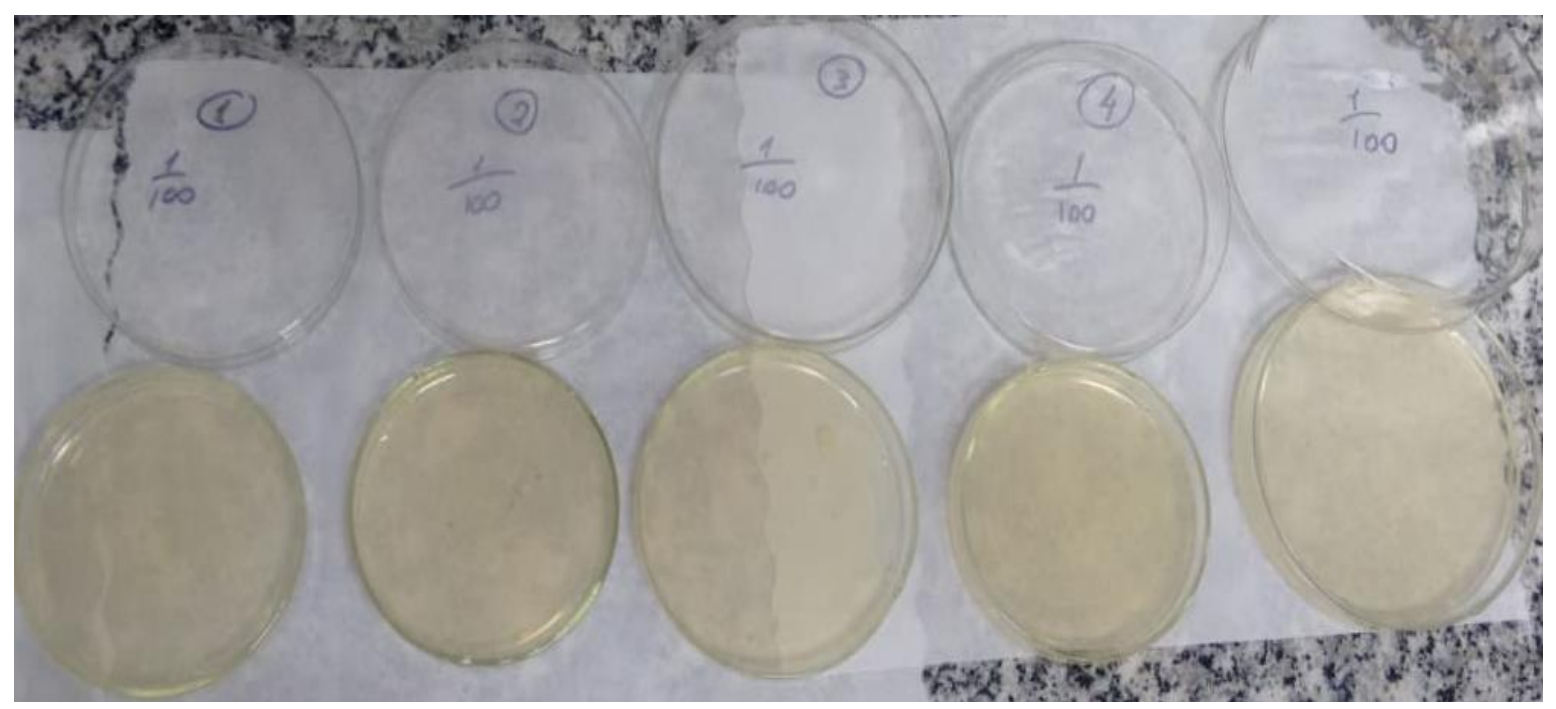

Figura 5. Semeadura em placa com diluição de 1:100 Fonte: elaborada pelo 
A concentração inibitória mínima (CIM) é a concentração mais baixa de um produto que impede o crescimento visível de uma bactéria, sendo uma técnica altamente confiável para avaliar o poder bactericida de determinado reagente (TRIPATHI, 2013). De acordo com os resultados apresentados, pode-se inferir que o óleo extraído da folha do E. urograndis possui efeito antimicrobiano positivo, pois as bactérias Staphylococcus aureus foram sensíveis após entrar em contato com o óleo, principalmente na diluição de 1:100.

Segundo estudo anterior in vivo e in vitro os óleos essenciais e polissacarídeos extraídos do eucalipto demonstram propriedades herbicidas, anti-inflamatórias, anti-oxidantes, anticancerígenas, anti-bacterianas, anti-virais e anti-fúngicas dependendo da localização geográfica e das espécies de eucalipto (MOTA et al. 2015).

As bactérias do gênero Escherichia coli (E. coli) e Staphylococcus aureus (S. aureus) são patógenos oportunistas que causam infecções graves e potencialmente fatais em pacientes imuno comprometidos. A bactéria gram-positiva S. aureus pode provocar doenças, que vão desde infecções simples, até infecções graves como pneumonia, meningite, endocardite, síndrome do choque tóxico e septicemia (TRABULSI et al., 2005). A bactéria gram-negativa E. coli está presente no intestino humano e está associada com infecções do trato urinário inferior e septicemia (ZHANEL et al., 2005).

Vários estudos documentaram taxas crescentes de resistência em $S$. aureus e E. coli a antibióticos (NIKAIDO et al., 2009), dessa forma, é de grande relevância que as pesquisas avancem com o intuito de propor alternativas para o tratamento de infecções ocasionadas por bactérias resistentes (MOTA et al., 2015).

Os resultados do presente estudo sugerem que a utilização do óleo extraído do $E$. urograndis pode representar uma possível alternativa para o tratamento de infecções ocasionadas por bactérias resistentes à antibióticos. No entanto, estudos mais aprofundados inclusive envolvendo partes vegetais da espécie, devem ser realizados devido à escassez de pesquisas que avaliam o poder antimicrobiano do óleo de E. urograndis.

\section{Considerações Finais}

As espécies do gênero Eucalyptus são amplamente utilizadas com finalidades medicinais, devido aos seus componentes ativos presentes nas plantas. Dessa forma o óleo extraído da folha do Eucalyptus urograndis, tem relevante importância no desenvolvimento de produtos farmacêuticos, pois apresentam poder antimicrobiano. 
O presente estudo avaliou o potencial antibacteriano do óleo extraído da folha do Eucalyptus urograndis através da técnica de disco-difusão, concentração inibitória mínima e confirmação com a semeadura em placa. Os resultados demonstraram que a diluição na proporção de 1:100 se mostrou a mais eficiente na inibição do crescimento de bactérias do gênero Staphylococcus aureus. Não foi possível visualizar a formação de halo com a utilização das bactérias Staphylococcus epidermides e E.coli.

Assim, sugere-se que o óleo extraído do Eucalyptus urograndis, representa considerável alternativa para o tratamento de infecções ocasionadas por Staphylococcus aureus, especialmente nas infecções resistentes à antibióticos convencionais. Entretanto, estudos mais aprofundados devem ser realizados á respeito deste tema, devido à escassez de experimentos realizados com a utilização do óleo extraído da folha do Eucalyptus urograndis, no tratamento de doenças infecciosas.

\section{Referências}

ANGIOSPERM PHYLOGENY GROUP. An update 4. of the angiosperm phylogeny group classification for the orders and families of flowering plants: APG III. Bot J LinSoc, v.161, n. 2, p. 105-21, out. 2009.

BACHIR, RG; BENALI, M. Antibacterial activity of the essential oils from the leaves of Eucalyptus globulus against Escherichia coli and Staphylococcus aureus. Asian Pac J Trop Biomed. 2012 Sep; 2(9): 739-742.

BARRY, A.L. Procedures and theoretical considerations for testing antimicrobial agents in agar media. In: Lorian, Antibiotics in Laboratory Medicine. 3. ed. Baltimore: The Williams \& Wilkins Co., Md, 1991.

BAUER, A.W. et al. Antibiotic susceptibility testing by a standardized single disk method. Am. J. Clin. Microbiol. v. 40, p. 2413-5, 1966.

BRASIL . Ministério da Saúde. Secretaria de Ciência, Tecnologia e Insumos Estratégicos. Departamento de Assistência Farmacêutica. Política nacional de plantas medicinais e fitoterápicos / Ministério da Saúde, Secretaria de Ciência, Tecnologia e Insumos Estratégicos, Departamento de Assistência Farmacêutica. - Brasília: Ministério da Saúde, 2006. 60 p

BRISOLA, S.H; DEMARCO, D. Análise anatômica do caule de Eucalyptusgrandis, E. urophylla e E. grandis $\mathbf{x}$ urophylla: desenvolvimento da madeira e sua importância para a indústria. 2011.

BURT, S. Essential oils: their antibacterial properties and potential applications in foods - a review. International Journal of Food Microbiology. 2004; 94:223-53.

CARNEIRO, M.F.; et al. Tendências dos estudos com plantas medicinais no Brasil. RevSapiê: Soc Sab PrátEduc, v. 3, n. 2, p. 44-75, 2014. 
DE PINHO, L. et al. Atividade antimicrobiana de extratos hidroalcoolicos das folhas de alecrimpimenta, aroeira, barbatimão, erva baleeira e do farelo da casca de pequi. Ciência Rural, v. 42, n. $2,2012$.

DUARTE, P.L.; et al. Constituintes químicos e efeito ecotoxicológico de extratos de folhas de Eucalyptusurograndis. RevCientDeptoQuím Exatas, v. 1, p. 19-26, 2010.

FARIA, R.J.; et al. Desenvolvimento de Eucaliptus urograndis no município de CorumbáGO.Ensaios e Ciência: Ciências Biológicas, Agrárias e da Saúde, v. 17, n. 2, 2013.

FUQUA, C., WINANS, S.C., GREENBERG, E.P. Census and consensus in bacterial ecosystems: the LuxR-LuxI family of quorum sensing transcriptional regulators. Annual Review of Microbiology. v. 50, p. 727-751, 1996.

GONÇALVES, A.L; ALVES FILHO L.; MENEZES H. Estudo comparativo da atividade antimicrobiana de extratos de algumas árvores nativas. ArqInstBiol 2005;72(3):353-8.

JORGENSEN, J.H. et al. Antimicrobial susceptibility tests: dilution and disk diffusion methods. In: Murray, R.P. et al. Manual of Clinical Microbiology. 7. ed. American Society for Microbiology, Washington DC, 1999, p.1526-43.

KIRBY E BAUER. Manual para antibiograma difusão em disco. Laborclin Produtos para Laboratórios Ltda. 2011.

LORENZI, H.; SOUZA, H. M. Plantas Ornamentais no Brasil. $3^{\circ}$ ed. Instituto Plantarum: Nova Odessa, 2001.

MOTA, Valéria de Siqueira; TURRINI, Ruth Natalia Teresa; POVEDA, Vanessa de Brito. Atividade antimicrobiana do óleo de Eucalyptus globulus, xilitol e papaína: estudo piloto. Rev. esc. enferm. USP, São Paulo, v. 49, n. 2, p. 0216-0220, Apr. 2015.

NATIONAL COMMITTEE FOR CLINICAL LABORATORY STANDARDS (NCCLS). Performance standards for antimicrobial disk susceptibility tests. Approved standards M7-A5. Wayne, PA, 2000.

NIKAIDO, H. Multidrugresistance in bacteria. AnnuRevBiochem. 2009;78:119-46.

PADOVANI CM, GRAZIANO KU, GOVEIA VR. Microbiological evaluation of different antiseptic povidone-iodine and chlorhexidine formulations after intentional contamination of containers. Rev Latino Am Enfermagem. 2008;16(6):1038-41.

PEREIRA, J.L. Composição química dos óleos essenciais de espécies de Eucaplyptus L' Herit (Myrtaceae). Universidade Federal de Viçosa, 2010.

RAHO GB, BENALI M. Antibacterial activity of the essential oils from the leaves of Eucalyptus globulus against Escherichia coli and Staphylococcus aureus. Asian Pac J Trop Biomed. 2012;2(9):739-42.

REIS, L.M.; RABELLO, B.R.; ROSS, C.; SANTOS, L.M.R. Avaliação da atividade antimicrobiana de antissépticos e desinfetantes utilizados em um serviço público de saúde. RevBrasEnferm. 2011;64(5):870-5. 
SARTOR, R. B. Modelagem, Simulação e Otimização de uma Unidade Industrial de Extração de Óleos Essenciais por Arraste a Vapor. Dissertação (Mestrado em Pesquisa e Desenvolvimento de Processos). Escola de Engenharia, Universidade Federal do Rio Grande do Sul. Porto Alegre, 2009.

SILVA, J.L.; Antifungal activity using medicinal plant extracts against pathogens of coffee tree. Revista brasileira de plantas medicinais, v.16, n. 3, p. 539-544, 2014.

SILVA, M. G. F.; Atividade antioxidante e antimicrobiana in vitro de óleos essenciais e extratos hidroalcóolicos de manjerona (Origanum majorana L.) e manjericão (Ocimum basilicum L.). 2011. 70 f. Trabalho de Conclusão de Curso - Curso Superior de Química - Bacharelado em Química Industrial/Licenciatura em Química, Universidade Tecnológica Federal do Paraná. Pato Branco, 2011.

SOBRAL, M.; PROENÇA, C.; SOUZA, M.; MAZINE, F.; LUCAS, E. Myrtaceae in: Lista de Espécies da Flora do Brasil. Jardim Botânico do Rio de Janeiro, Rio de Janeiro, 10 de jan. 2014.

TRABULSI, L. R.; ALTHERTHUM, F. Microbiologia. Staphylococcus aureus. São Paulo: Atheneu, 2005. cap. 20, p. 175-82.

TRIPATHI, K.D. Essentials of Medical Pharmacology 7th ed. New Delhi, India: Jaypee Brothers Medical Publishers. p. 696-697, 2013.

VITTI, A. M. S.; BRITO, J. O. Óleo essencial de Eucalipto, Ed. USP: São Paulo, 2003. In:Bruneton J.; Elementos de Fitoquimica y de Farmacognosia, Acribia: Zaragoza, 1992; Batista-Pereira, L. G.; Fernandes, J. B.; Corrêa, A. G.; da Silva, M. F. G. F.; Vieira, P. C.; J. Braz. Chem. Soc. 2006, 17, 555.

WARNKE, P.H; BECKER, S.T; PODSCHUN, R;SIVANANTHAN, S;SPRINGER, I.N; et al. The battle against multi-resistant strains: renaissance of antimicrobial essential oils as a promising force to fight hospital-acquired infections. J Craniomaxillofac Surg. 2009;37(7):392-7.

ZHANEL, G. G, et al. Antibiotic resistance in outpatient urinary isolates: Final results from the North American Urinary Tract Infection Collaborative Alliance (NAUTICA). Int J Antimicrob Agents. v. 26, p. 380-388, 2005.

\section{Como citar este artigo (Formato ABNT):}

CARDOSO, Raquel Cotrim; ALCÂNTARA, Allana Leão; SOUZA, Flavio Mendes de; ESPINHEIRA, Marcelo José Costa Lima. Potencial Antimicrobiano do Óleo da Folha de Eucalyptus urograndis Frente Stafilococus aureus. Id on Line Rev.Mult. Psic., 2019, vol.13, n.43, p. 989-1002. ISSN: 1981-1179.

Recebido: 02/12/2018;

Aceito: 04/12/2018 